\title{
Interfollicular Epidermal Stem Cells: Boosting and Rescuing from Adult Skin
}

\author{
Mariana T. Cerqueira, Ana M. Frias, Rui L. Reis, and Alexandra P. Marques
}

\begin{abstract}
Epidermal stem cells isolation struggle remains, mainly due to the yet essential requirement of well-defined approaches and markers. The herein proposed methodology integrates an assemblage of strategies to accomplish the enrichment of the interfollicular epidermal stem cells multipotent fraction and their subsequent separation from the remaining primary human keratinocytes culture. Those include rapid adherence of freshly isolated human keratinocytes to collagen type IV through the $\beta 1$-integrin ligand and RhoAssociated Protein Kinase Inhibitor Y- 27632 administration to the cultures, followed by an immunomagnetic separation to obtain populations based in the combined CD49fori $/ \mathrm{CD} 7 \mathrm{l}^{\mathrm{dim}}$ expression. Flow cytometry is the supporting method to analyze the effect of the treatments over the expression rate of early epidermal markers keratins $19 / 5 / 14$ and in correlation to $\mathrm{CD} 49 \mathrm{f}^{\text {bri }} / \mathrm{CD} 7 \mathrm{1}^{\mathrm{dim}}$ subpopulations. The stepby-step methodology herein described indulges the boosting and consecutive purification and separation of interfollicular epidermal stem cells from human keratinocytes cultures.
\end{abstract}

Key words Epidermal stem cells, Collagen IV, Rock inhibitor, Immunomagnetic separation, Flow cytometry

\section{Introduction}

Human keratinocytes (hKC) have a limited lifespan in culture that constraints their proliferative capacity and consequently their clinical potential. The long-term function of the skin equivalents generated in a Regenerative Medicine context can be limited by the length of time needed to obtain epithelial sheets in vitro, during which patient is highly susceptible to infection, and also by extensive culture that may lead to terminal differentiation of the hKC to be grafted, thus compromising its success. Therefore, the use of epidermal stem cells (EpSCs) that play an important role in cellular regeneration, wound healing, and neoplasm formation (1) for this purpose enlarges the possibility of providing an alternative and clinically relevant active source of biological material.

Despite a wide effort among stem cells biologists community (2-6), EpSCs isolation difficulty remains, mainly due to the 
insufficiency of molecular markers that distinguish these cells from other proliferative cells within skin basal layer, highlighting the need for defining approaches and a panel of markers to obtain specific and well-characterized cell populations. P63 is abundantly expressed by holoclones and therefore recognized as being also present in EpSCs playing an important role in morphogenesis and in the expression pattern of the cultures (7). It has been also proposed that EpSCs exhibit a characteristic keratin profile that includes the typical $\mathrm{K} 5$ and $\mathrm{Kl} 4$ expression of the basal layer but not of $\mathrm{Kl} / \mathrm{l} 0$ of the suprabasal layer cells. K19 appears also as an EpSCs-associated marker as it is expressed by cells present in the skin hair follicles bulge and in the deep epidermal rete ridges within thicker epidermis, being also expressed by a subpopulation of $\mathrm{hKC}$ in the human basal layer during proliferative lateral skin expansion (8).

Interestingly, the molecules related with cell-substratum adhesion are naturally meaningful as potential EpSCs markers, supported by the hypothesis that EpSCs require strong adherence to the basement membrane to maintain their stem cell characteristics or their position in the stem cell niche. (9). $\beta$ l-integrin was firstly identified in highly proliferating $\mathrm{KC}$ (holoclones) and was used to distinguish EpSCs and other basal cells (5). However, subsequent studies revealed that the majority of the cells of the basal layer in the human epidermis, EpSCs, and transient amplifying cells exhibit the expression of beta $\mathrm{l}$ integrin (10) and other putative markers such as the combination of CD49f ( $\alpha 6$-integrin) and CD7l (transferrin receptor) (5). Human epidermal cells have been thus divided into three different subsets, $\alpha 6^{\text {bri }} \mathrm{CD} 71^{\text {dim }}, \alpha 6^{\text {bri }} \mathrm{CD} 71^{\text {bri }}$, and $\alpha 6^{\text {dim }}$ expressing cells, the first being those with the highest proliferation rate and capability of long-term epidermal renewal (11), even at a limited dilution.

Despite the high importance of EpSCs, they constitute between $1 \%$ and $10 \%$ of the basal layer cells and, independently of the standardization of a characteristic panel of markers, boosting this population in culture through enrichment methods is a major demand. The involvement of Rho-Associated Protein Kinase (Rock) in tissue homeostasis, namely in the epidermis, is already recognized. Regardless of the unconsciousness of the exact timing of events, the key role that Rock plays in determining hKC fate was clearly demonstrated. By blocking Rock function, an inhibition of hKc terminal differentiation and an increase in cell proliferation was observed (12). It has also been shown that Rock inhibitor (Rocki) leads to an increased number of hKC in primary cultures that can survive and grow forming healthy colonies, thus suggesting its effect in boosting the cells exhibiting stem cell behavior (13) yet retaining the ability to differentiate and to form a stratified epithelium in adequate organotypic models (14). The herein proposed methodology describes an assemblage of strategies to accomplish enrichment and further purification of the EpSCs multipotent fraction present in 
hKC primary cultures. The procedure combines the rapid adherence of primary hKC to $\beta \mathrm{l}$-integrin ligand in collagen type IV and the administration of Rho-Associated Protein Kinase (Rock) Inhibitor Y- 27632 to the culture, together with subsequent immunomagnetic separation of subpopulations combining CD49f bri $/ C D 71^{\text {dim }}$ expression.

\section{Materials}

2.1 Labware (see Note 1)

\subsection{Reagents}

Petri dishes (Greiner Bio One, Cat. No. 391-2080).

Forceps (RSG, Cat. No. 311.105).

Surgical scissors (RSG, Cat. No. 101.130).

Cell culture flasks $\left(75 \mathrm{~cm}^{2}, 150 \mathrm{~cm}^{2}\right)$ (BD Falcon, Cat. No. 353136 , 353028).

6-well culture plates (BD Falcon, Cat. No. 353224).

15 mL Falcon tubes (BD Falcon, Cat. No. 352097).

$50 \mathrm{~mL}$ Falcon tubes (BD Falcon, Cat. No. 352070).

Flow cytometry tubes (BD Falcon, Cat. No. 352052).

Pipettes (Corning Science Products, Cat. No. 4489).

Cell strainers of $100 \mu \mathrm{m}$ pore size (BD Falcon, Cat. No. 352360).

Eppendorf tubes $1.5 \mathrm{~mL}$ (Laborspirit, Cat. No. 200400P).

DynaMag $^{\mathrm{TM}}-2$ magnet (Invitrogen, Cat. No. 123-21D).

$0.22 \mu \mathrm{m}$ pore membrane filters (Sarsted, Cat. No. 83.1823.101).

Phosphate buffer saline (PBS) (Sigma, Cat. No. P4417).

Distilled water $\left(\mathrm{diH}_{2} \mathrm{O}\right)$.

Antibiotic/antimycotic solution (Gibco, Cat. No. 15240062).

Dispase (BD Biosciences, Cat. No. 354235).

Trypsin-EDTA (Gibco, Cat. No. 25300-062).

Keratinocyte Serum Free Medium (KSFM) Kit with 1-Glutamine, EGF, and BPE (Gibco, Cat. No. 17005-075).

Y-27632 dihydrochloride monohydrate (Sigma, Cat. No. Y0503). Acetic acid (vWR, Cat. No. 20104.334).

Human placenta collagen type IV (Sigma, Cat. No. C5533).

Bovine serum albumin (BSA) (Sigma, Cat. No. A2153).

Dynabeads M-450 Epoxy (Life Technologies, Cat. No. 14011).

Sodium phosphate (Sigma, S0876).

Permeabilization buffer (10×) (eBioScience, Cat No. 00-8333).

CD49f-APC antibody (eBioscience, Cat. No. 17-0495-82). 


\subsection{Reagents Setup}

CD71-PE antibody (BD Biosciences, Cat. No. 555537).

Cytokeratin 19-AF488 antibody (ExBio, Cat. No. A4-120-C100).

Cytokeratin 14-FITC antibody (AbD Serotec, MCA890F).

Keratin 5 antibody (Covance, Cat. No. PRB-160P).

Alexa Fluor 488 Goat anti-Rabbit (Invitrogen, Cat. No. A-11008).

Formaldehyde (vWR, Cat. No. ALFA33314K2).

Sodium azide (Sigma, Cat. No. 13412).

1. Dispase stock solution (25 $\mathrm{U} / \mathrm{mL})$ : dilute dispase, 1:2 in PBS (see Note 2).

2. Collagen $I V$ stock solution ( $1 \mathrm{mg} / \mathrm{mL}$ ): Add $5 \mathrm{~mL}$ of $0.25 \%$ acetic acid and let to dissolve overnight at $4^{\circ} \mathrm{C}$ (see Notes 2 and 3 ).

3. Rocki stock solution (1 mM): Reconstitute $1 \mathrm{mg}$ of Y-27632 dihydrochloride monohydrate in $2.96 \mathrm{~mL}$ of $\mathrm{diH}_{2} \mathrm{O}$.

4. Dynabeads buffer 1: prepare a buffer of 0.1 M Sodium phosphate in $\operatorname{diH}_{2} \mathrm{O}$ and adjust $\mathrm{pH}$ to 7.4-8.0 (see Note 4)

5. Dynabeads buffer 2: make a $0.1 \%$ BSA solution in PBS and adjust the $\mathrm{pH}$ to 7.4 .

6. Coating of immunomagnetic beads with CD71 and CD49f antibodies (see Note 5)

6.1 Transfer $10 \mu \mathrm{L}$ of dynabeads to an eppendorf tube.

6.2 Place the tube in a magnet for a minute and discard the supernatant. Remove the tube from the magnet.

6.3 Resuspend the beads in $50 \mu \mathrm{L}$ of Dynabeads buffer 1 and add $4 \mu \mathrm{L}$ of CD71 or $2 \mu \mathrm{L}$ of CD49f antibody.

6.4 Incubate for 16-24 h at room temperature with gentle tilting and rotation.

6.5 Repeat step 6.2 and resuspend beads in Dynabeads buffer 2 .

7. Permeabilization buffer: Dilute permeabilization buffer $(10 \times)$ in $\mathrm{diH}_{2} \mathrm{O}$ to obtain a $\mathrm{I} \times$ working solution, store at $4^{\circ} \mathrm{C}$.

8. Labeling buffer: Prepare a 3\% BSA solution in PBS.

9. Acquisition buffer: Make a $1 \%$ formaldehyde and $0.1 \%$ Sodium azide solution in PBS, filter $(0.22 \mu \mathrm{m}$ pore membrane $)$, and store at RT.

10. Antibiotic/antimycotic solution: Make a $1 \%$ antibiotic solution in PBS

11. Dispase working solution $(2.5 \mathrm{U} / \mathrm{mL})$ : Dilute $1: 10$ of stock dispase solution in $1 \%$ solution of antibiotic/antimycotic in PBS

12. Rocki working solution $(10 \mu M)$ : Dilute Rocki stock solution (1 mM) 1:100 in KSFM, in order to have KSFM supplemented with $10 \mu \mathrm{M}$ Rocki. 
3 Methods

\subsection{Isolation of Human Keratinocytes from Adult Skin}

3.1.1 Processing Human Skin

3.1.2 Epidermal-Dermal Separation by Dispase

3.1.3 Isolation of Human Keratinocytes: Digestion of Epidermis with Trypsin

\subsection{EpSCs} Enrichment Strategies (see Note 6)

\subsubsection{Rapid Adherence to Collagen IV}

3.2.2 Rock Inhibitor
1. Remove the exceeding fat tissue from the dermis with scissors and scalpel.

2. Wash the skin samples with antibiotic/antimycotic solution ( $\pm 20 \mathrm{~s})$.

3. Cut skin into $0.5 \mathrm{~cm}^{2}$ pieces.

Incubate skin pieces in dispase working solution $(2.5 \mathrm{U} / \mathrm{mL})$ overnight at $4^{\circ} \mathrm{C}$ in a $250 \mathrm{~mL}$ flask.

After incubation place the skin samples on a Petri dish and peel off epidermis from dermis using two pairs of forceps.

1. Place epidermis (dermal side up) in a new Petri dish.

2. Add $0.05 \%$ trypsin-EDTA.

3. Incubate the samples at $37^{\circ} \mathrm{C}$ for $5-7 \mathrm{~min}$.

4. Add an equal amount of KSFM.

5. Scrape of cells carefully with a cell scraper.

6. Pipette rigorous up and down several times.

7. Poor cell suspension trough a $100 \mu \mathrm{m}$ pore size cell strainer into a $50 \mathrm{~mL}$ Falcon tube.

8. Wash with PBS, passing the liquid through the $100 \mu \mathrm{m}$ pore size cell strainer.

9. Centrifuge for $5 \mathrm{~min}$ at $290 \times \mathrm{g}$.

10. Wash pellet with $5 \mathrm{~mL}$ of PBS.

11. Poor cells trough a $100 \mu \mathrm{m}$ pore size cell strainer into a $50 \mathrm{~mL}$ Falcon tube.

12. Centrifuge for $4 \mathrm{~min}$ at $290 \times g$.

13. Resuspend cell pellet (hKC) in KSFM.

1. Coat tissue culture surface with collagen IV, by incubating $5 \mu \mathrm{g} / \mathrm{cm}^{2}$ at $37^{\circ} \mathrm{C}$, for at least $1 \mathrm{~h}$ (see Note 3 ).

2. Wash with PBS.

3. Plate $2 \times 10^{4} \mathrm{hKC} / \mathrm{cm}^{2}$ in KSFM.

4. Change medium every $2-3$ days and keep the culture until $80 \%$ confluent.

1. Plate $2 \times 10^{4}$ cells $/ \mathrm{cm}^{2}$ in Rocki working solution $(10 \mu \mathrm{M})$.

2. Change medium every 2-3 days; keep them in culture until $80 \%$ confluent.

1. Perform steps 1 and 2 described in section 3.2.1.

2. Proceed as described in section 3.2.2. 


\subsection{Intermediate Analysis}

\section{$3.4 C D 71-/ C D 49 f^{+}$ Rescuing: Immunomagnetic Selection}

3.4.1 Depletion of $\mathrm{CD} 71^{+}$ Cells

3.4.2 Positive Selection of CD49f+ Cells Among CD71- Population
An intermediate analysis of a fraction of the obtained cells after each treatment should be performed in order to assess the effect in the increased fraction of interest-EpSCs fraction. Therefore in this section a flow cytometry protocol using a combination of CD49f-APC and CD71-PE markers is described.

1. Harvest the adherent cells cultured under the described conditions with trypsin-EDTA.

2. Transfer cells to a $15 \mathrm{~mL}$ falcon tube and add labeling buffer up to $10 \mathrm{~mL}$.

3. Centrifuge cell suspension at $200 \times g$ for $5 \mathrm{~min}$.

4. Count cells using a hemocytometer.

5. Discard supernatant and resuspend cell pellet to a concentration of $0.5-10^{6}$ cells $/ \mathrm{mL}$ in fresh labeling buffer.

6. Add $100 \mu \mathrm{L}$ of cell suspension to each flow cytometry tube (see Note 7).

7. Add $4 \mu \mathrm{L}$ of CD71-PE and $2 \mu \mathrm{L}$ CD49f-APC antibodies; reserve one tube per condition without antibody as control.

8 . Incubate $30 \mathrm{~min}$ at room temperature.

9. Wash by adding $2 \mathrm{~mL}$ of PBS per tube and centrifuge at $250 \times g$ for $3 \mathrm{~min}$.

10. Resuspend cell pellets in $500 \mu \mathrm{L}$ of acquisition buffer.

11. Acquire data in flow cytometer.

12. Analyze simultaneous expression of CD71 and CD49f (Fig. 1).

1. Wash CD71 coated beads by placing the tubes in a magnet for $1 \mathrm{~min}$, discarding the supernatant and adding $1 \mathrm{~mL}$ of Dynabeads buffer 2, twice.

2. Incubate the cells harvested on Subheading 3.3, step 1 and resuspended in Dynabeads buffer 2 with the washed CD71 beads for $30 \mathrm{~min}$ at $2-8^{\circ} \mathrm{C}$ with gentle tilting and rotation.

3 . Place the tubes in a magnet for $2 \mathrm{~min}$.

4. Transfer the supernatant containing the unbound cells to a fresh $15 \mathrm{~mL}$ Falcon tube $\left(\mathrm{CD}^{-} \mathrm{1}^{-}\right.$cell fraction).

5. Count cells using a hemocytometer.

6. Plate $2 \times 10^{4}$ cells $/ \mathrm{cm}^{2}$ in new tissue culture vessels /flasks with the correspondent treatments (described in Subheading 3.2).

7. Culture cells until $80 \%$ confluent by changing medium 2-3 days.

1. Harvest CD71- cells with trypsin-EDTA and resuspend them in Dynabeads buffer 2.

2. Wash CD49f coated beads by placing the tubes in a magnet for $1 \mathrm{~min}$, discarding the supernatant and adding $1 \mathrm{~mL}$ of Dynabeads buffer 2, twice. 

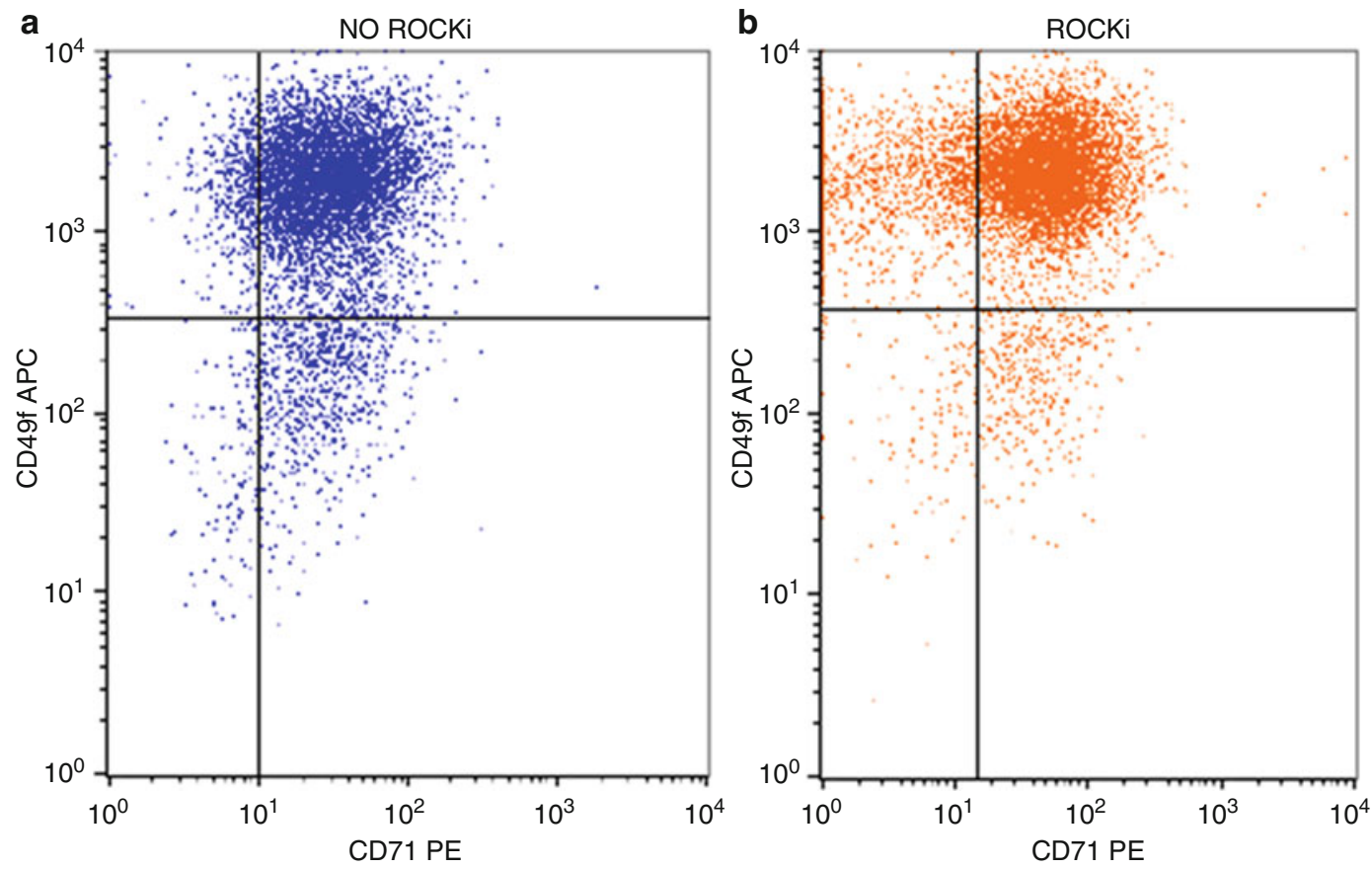

Fig. 1 Dot plots of CD49f/CD71 staining on human keratinocytes isolated from the same human sample and cultured without any treatment (a) and after EpSCs enrichment with Rocki (b), showing an increase of the population of interest by the differential expression of CD49frri/CD71 ${ }^{\mathrm{dim}}(6.20 \%$ in a and $10.37 \%$ in $\mathbf{b})$

\subsection{Analysis}

3.5.1 Direct Staining
3. Incubate $\mathrm{CD} 71^{-}$cells for $20 \mathrm{~min}$ at $2-8^{\circ} \mathrm{C}$ with gentle tilting and rotation.

4. Place the tubes in a magnet for $2 \mathrm{~min}$.

5. Discard the supernatant and gently wash the bead-bounded cells, four times, by adding $1 \mathrm{~mL}$ of Dynabeads buffer 2 .

6. Place the tubes in the magnet for $1 \mathrm{~min}$ and discard the supernatant.

7. Resuspend the cells in fresh KSFM.

8. Plate $2 \times 10^{4}$ cells $/ \mathrm{cm}^{2}$ in new tissue culture vessels/flasks with the correspondent treatments (described in Subheading 3.2) for further cell expansion and analysis.

The analysis of the expression of the early epidermal markers on the obtained cell fraction by flow cytometry is advisable to validate the success of the employed strategies. Thus, this section comprises the protocol for identifying the expression of the intracellular markers using Cytokeratin 19-AF488 and Cytokeratin 14-FITC, and Keratin 5, respectively by direct and indirect staining.

Follow the protocol from Subheading 3.3, steps $1-11$, using $5 \mu \mathrm{L}$ of Cytokeratin 19-AF488 and $4 \mu \mathrm{L}$ of Cytokeratin 14-FITC in separate tubes. 

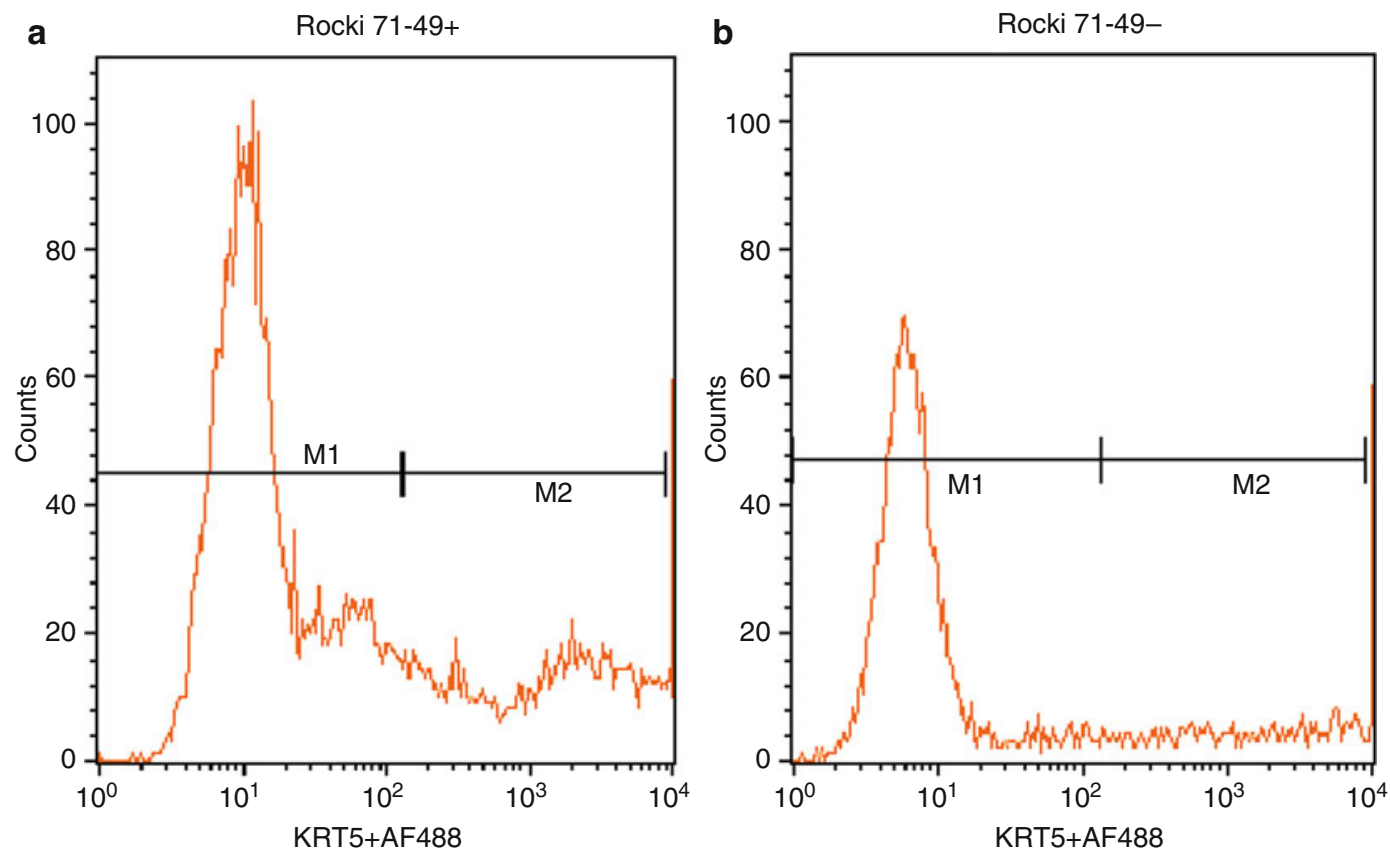

Fig. 2 Expression fluorescence profile of Keratin 5 (early epidermal marker) in both CD71-/ $\alpha 6+$ cells (25.45\%) (a) and CD71-/ $\alpha 6$ - (17.42\%) (b), showing the higher expression of $\mathrm{K} 5$ in the fraction of interest, thus illustrating its early differentiation stage

1. Follow the protocol from Subheadings 3.3, steps 1-6.

2. Incubate cells with $200 \mu \mathrm{L}$ of permeabilization buffer for $10 \mathrm{~min}$ at RT.

3. Centrifuge for $5 \mathrm{~min}$ at $250 \times g$ and remove supernatant.

4. Resuspend cells in $200 \mu \mathrm{L}$ of keratin 5 antibody diluted 1:500 in labeling buffer.

5 . Incubate for $\mathrm{l} \mathrm{h}$ at room temperature.

6. Wash by adding $2 \mathrm{~mL}$ of PBS, centrifuge at $250 \times g$ for $5 \mathrm{~min}$, and remove supernatant.

7. Resuspend cells in $200 \mu \mathrm{L}$ of Alexa-fluor-labeled secondary antibody diluted 1:500 in labeling buffer.

8 . Incubate $45 \mathrm{~min}$ at $4^{\circ} \mathrm{C}$ protected from light.

9. Wash by adding $2 \mathrm{~mL}$ of PBS, centrifuge at $250 \times g$ for $5 \mathrm{~min}$, and remove supernatant.

10. Resuspend cell pellets in $500 \mu \mathrm{L}$ of acquisition buffer.

11. Acquire data in flow cytometer (Fig. 2). 
4 Notes

1. All the labware has to be sterilized prior use.

2. It is recommended to make aliquots that should be kept at $-20^{\circ} \mathrm{C}$, avoiding repeated freeze-thawing.

3. Coating with collagen IV can be previously performed incubating solution overnight at $4^{\circ} \mathrm{C}$, without drying.

4. Alternatively, a solution of $0.1 \mathrm{M}$ sodium borate sulfate in $\mathrm{diH}_{2} \mathrm{O}, \mathrm{pH} 7.4-8$, can be used as buffer 1 .

5. This protocol is adapted from the section "coupling of ligands to dynabeads" of the Dynabeads m-450 Epoxy manufacturer's instructions.

6. Cells cultured, in these different treatments, present distinct adherence and proliferation rates. No specific treatment, in which cells are cultured in noncoated plates and in KSFM, should be performed as a control. hKC cultured in Rocki and No treatment take almost $\mathrm{l}$ week to first adhere.

7. The remaining cells should be used as described in Subheading 3.4 and kept in culture for comparison purposes in the end of the experiment.

\section{References}

1. Blanpain C, Lowry WE, Geoghegan A, Polak L, Fuchs E (2004) Self-renewal, multipotency, and the existence of two cell populations within an epithelial stem cell niche. Cell 118:635-648

2. Lau K, Paus R, Tiede S, Day P, Bayat A (2009) Exploring the role of stem cells in cutaneous wound healing. Exp Dermatol 18:921-933

3. Watt FM, Lo Celso C, Silva-Vargas V (2006) Epidermal stem cells: an update. Curr Opin Genet Dev 16:518-524

4. Blanpain C, Fuchs E (2006) Epidermal stem cells of the skin. Annu Rev Cell Dev Biol 22:339-373

5. Li A, Simmons PJ, Kaur P (1998) Identification and isolation of candidate human keratinocyte stem cells based on cell surface phenotype. Proc Natl Acad Sci USA 95:3902-3907

6. Taylor G, Lehrer MS, Jensen PJ, Sun TT, Lavker RM (2000) Involvement of follicular stem cells in forming not only the follicle but also the epidermis. Cell 102:451-461

7. Pellegrini G, Dellambra E, Golisano O, Martinelli E, Fantozzi I, Bondanza S, Ponzin D, McKeon F, De Luca M (2001) p63 identifies keratinocyte stem cells. Proc Natl Acad Sci USA 98:3156-3161

8. Pontiggia L, Biedermann T, Meuli M, Widmer D, Bottcher-Haberzeth S, Schiestl C, Schneider J, Braziulis E, Montano I, Meuli-Simmen C, Reichmann E (2009) Markers to evaluate the quality and self-renewing potential of engineered human skin substitutes in vitro and after transplantation. J Invest Dermatol 129:480-490

9. Alonso L, Fuchs E (2003) Stem cells of the skin epithelium. Proc Natl Acad Sci USA 100(Suppl 1):11830-11835

10. Kaur P, Li A (2000) Adhesive properties of human basal epidermal cells: an analysis of keratinocyte stem cells, transit amplifying cells, and postmitotic differentiating cells. J Invest Dermatol 114:413-420

11. Schluter H, Paquet-Fifield S, Gangatirkar P, Li J, Kaur P (2011) Functional characterization of quiescent keratinocyte stem cells and their progeny reveals a hierarchical organization in human skin epidermis. Stem Cells 29:1256-1268

12. McMullan R, Lax S, Robertson VH, Radford DJ, Broad S, Watt FM, Rowles A, Croft DR, Olson MF, Hotchin NA (2003) Keratinocyte differentiation is regulated by the Rho and ROCK signaling pathway. Curr Biol 13: 2185-2189

13. Terunuma A, Limgala RP, Park CJ, Choudhary I, Vogel JC (2010) Efficient procurement of epithelial stem cells from human tissue specimens using a rho-associated protein kinase inhibitor Y-27632. Tissue Eng Part A 16:1363-1368

14. Chapman S, Liu X, Meyers C, Schlegel R, McBride AA (2010) Human keratinocytes are efficiently immortalized by a Rho kinase inhibitor. J Clin Invest 120:2619-2626 